Brit. J. industr. Med., 1955, 12, 21.

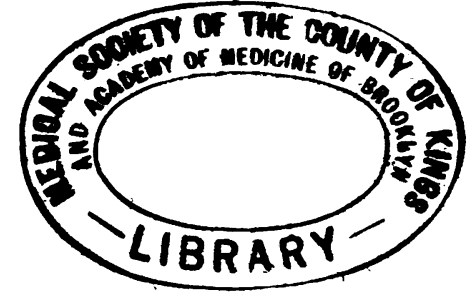

\title{
MANGANESE POISONING IN MOROCCAN MINERS
}

\author{
BY \\ J. RODIER \\ From the Department of Toxicology in the Institute of Hygiene, Morocco
}

(RECEIVED FOR PUBLICATION JULY 28, 1954)

While there is very little in the literature about criminal or accidental manganese poisoning, manganese ores and their industrial applications give rise to a number of cases of occupational poisoning. The historical background of the condition has already been reviewed in a previous paper (Rodier and Rodier, 1949) but it should be noted that this occupational disease has been recognized since 1837 when Couper of Glasgow observed the first cases among five manganese ore crushers. He described a series of nervous phenomena : muscular weakness, paraplegia, tremor of the extremities, a tendency to lean forward while walking, whispering speech, and salivation.

Since then a number of writers have made further observations and recognized manganese as a poison affecting the central nervous system. It is less well known than other metallic poisons. It continues to be rare since only a limited number of workers come in contact with manganese in a dangerous form. The symptoms, which progress as a rule to total disablement, render it one of the most serious occupational hazards. It poses important social problems, as much concerning the rehabilitation of partially incapacitated labourers, as the care of the sick man and his family by the community.

\section{Manganese and its Ores}

Manganese is not found in a free state in nature but its minerals are quite numerous. Manganese dioxide has been known since remote antiquity and Pliny mentions its use in glass making. In 1774 , in Stockholm, Scheele defined the nature of the metal after three long years of research. After Bergman's thesis (1774) the chemical existence of manganese was finally established. It was in $\mathbf{1 7 8 5}$ that Guyton de Morveau proposed the name "manganese" to distinguish the metal called "magnesium" by Bergman. The metal is extremely diffused in nature under mineral and organic forms. Some writers consider it invariably present in arable soil, and it seems to be an almost constant constituent of living matter.

Although manganese in its pure form is of limited use, its derivatives are much in demand in industry. The alloys which it forms with certain metals, and to which it confers remarkable properties, give it great industrial importance. The metal industry could not dispense with it, and uses an average of 14 kilograms of manganese per ton of ordinary steel. Alloys of iron and manganese (ferro-manganese and speigel) play a very important role in steel works as desulphurants and de-oxidisers. Ferro-manganeses also serve in the preparation of numerous special steels with copper, aluminium, and other metals.

Outside metallurgy certain special categories of derivatives called " chemical manganese ", including those varieties richest in bioxide, are used as depolarizers in the manufacture of dry cells. The pyrolusite is used in small quantities in the glass industry as a decolorizer under the name of " glass maker's soap". Its oxidizing action on the unsaturated fatty acids is used in manufacturing quickdrying paints. The chemical industry also uses the pyrolusite as a catalyst and an oxidizer. Finally, in electro-technology manganese is used for making certain types of electrodes for electric soldering. If at the present time the U.S.S.R. share is estimated to be perhaps $3,000,000$ tons, world production is of the order of $7,000,000$ tons of saleable ore. Of this total the British Commonwealth easily leads with 2,400,000 tons, thanks to India, the Union of South Africa, and the Gold Coast. Other producers are Morocco (5\%), Brazil (3.5\%), Egypt (2.5\%), and Cuba (2\%). The U.S.A., a big consumer, produces very little, less than 100,000 tons a year.

\section{Production of Manganese in Morocco}

Production in Morocco is developed under the influence of the French Protectorate. From 760 
tons in 1922 it reached by 1953420,000 tons, of which 40,000 tons are chemical salts.

The mines of Imini, Bou-Arfa, and Tiouine (in order of importance) furnish $90 \%$ of Moroccan production. Geologically the deposits of manganese in Morocco are of two principal types, sedimentary deposits and seam deposits.

The first are the more important and make up the greater part of the country's production. They are situated in cretaceous terrains such as Imini and Talsdremt, liassic as at Bou-Arfa, or cambrian as at Tiouine (Rodier, 1950). Reserves of these deposits would amount to $15,000,000$ tons.

\section{Exploitation}

The techniques vary in different mines. Most of the workings at Imini are underground. The friable and powdery nature of the ore only very rarely calls for blasting or the use of rock-drilling machines. Formerly excavation was by hand-pick but now hand-picks have been replaced by pneumatic drills. The ore is removed in tubs winchhoisted up an incline. One part only is worked as open-cast. The mineral extracted is made up of pyrolusite very rich in manganese. Formerly the ore was screened and hand-picked but now this process is replaced by pneumatic washing. The inconvenience of this system is to get rid of the quantities of dust so it has been necessary to add to this an elaborate apparatus, which seems satisfactory, for suppressing the dust.

The powdery nature of the ore renders its transport difficult and is a serious handicap to its use in blast furnaces. It is thus necessary to treat it in Casablanca in a "sinterization" works using a Dwight-Lloyd machine.

At Bou-Arfa working is by horizontal terraced trenches. The general character of the ore is rather friable and as much as a third of production is made up of small stuff.

At Tiouine workings are entirely underground and mined by the gallery-and-pillar method. Because of the hardness of the rock, excavation is by blasting after the blast holes have been bored by rock drills. The spoil is removed by mine tubs on the level, which are subsequently pulled to the surface by electric winches. Sorting of the large blocks of ore is done by hand-picking.

\section{Personnel}

The employees of the mines vary according to the size of the different centres. Table 1 gives their distribution according to their categories and the mines :
TABLE 1

DISTRIBUTION OF MINE WORKERS

\begin{tabular}{|c|c|c|c|c|c|c|}
\hline & \multicolumn{2}{|c|}{ Imini } & \multicolumn{2}{|c|}{ Bou-Arfa } & \multicolumn{2}{|c|}{ Tiouine } \\
\hline & Basic & Day & Basic & Day & Basic & Day \\
\hline $\begin{array}{l}\text { Men } \\
\text { Youths under } 20 \\
\text { Women } \\
\begin{array}{l}\text { Office workers and } \\
\text { supervisory staff }\end{array}\end{array}$ & $\begin{array}{r}895 \\
90 \\
20\end{array}$ & $\begin{array}{r}421 \\
80 \\
179 \\
57\end{array}$ & $\begin{array}{r}804 \\
19 \\
- \\
-\end{array}$ & $\begin{array}{r}362 \\
9 \\
46 \\
69\end{array}$ & $\begin{array}{r}398 \\
52 \\
- \\
-\end{array}$ & $\begin{array}{r}189 \\
24 \\
99\end{array}$ \\
\hline Total & \multicolumn{2}{|c|}{1,742} & \multicolumn{2}{|c|}{1,309} & \multicolumn{2}{|c|}{798} \\
\hline
\end{tabular}

About 4,000 workers are thus employed in the industry. While the numbers of Europeans are relatively fixed, the numbers of local day-labourers fluctuate a good deal. Absenteeism is considerable, especially at festivals and harvest times. Numbers employed in other workings, especially the seam deposits, amount to some 500 but statistics of these are difficult to establish because the workings are constantly changing as the seams peter out.

\section{Aetiology}

The 150 cases of poisoning which I have seen have all been in underground workers. Of the various jobs at the face, undoubtedly drilling blast holes is most dangerous. This work, which used to be done by sledge hammer and hand bar, is now only carried out by pneumatic drills. Among my patients 132 were miners using these drills. The 19 others were underground labourers who mostly worked in the immediate proximity of the drills. A few of them were specialists in tamping and firing the explosives. They were thus called upon to stay in an atmosphere full of the dust resulting from blasting.

It is thus clear that the incidence of the poisoning is intimately linked with operations for pulverizing the ore and that this begins with boring blast holes and blasting itself. This agrees with the observations of other writers on the subject who have referred to the condition as " manganese crushers' disease".

\section{The Neurological Syndrome}

The Onset of the Disease.-Table 2 shows the delay among patients before the onset of symptoms. These details were obtained in 115 of the patients.

Table 2 also shows that the onset may be quite soon after one or more months of work. Usually it comes on after one to two years of exposure to manganese and only rarely after so long as a decade. In general its onset is slow and progressive, but occasionally it will appear suddenly within a week accompanied by severe lumbar pain. 
TABLE 2

DELAY BEFORE ONSET OF DISEASE

\begin{tabular}{l|c}
\hline Time Employed & No. of Cases \\
\hline 1 to 3 months & $6(5 \cdot 2 \%)$ \\
3 to 6 months & $16(13.85 \%)$ \\
6 to 12 months & $15(13.05 \%)$ \\
1 to 2 years & $28(24 \cdot 35 \%)$ \\
2 to 3 years & $14(12 \cdot 15 \%)$ \\
3 to 5 years & $14(12.2 \%)$ \\
5 to 10 years & $20(17 \cdot 46 \%)$ \\
Over 10 years & $2(1.70 \%)$ \\
\hline
\end{tabular}

The disease can be described in three phases: the prodromal period; an intermediate phase corresponding to the onset of the earliest objective symptoms ; and the period of complete establishment characterized by severe disorders leading to permanent disablement.

Prodromal Period.-The first disorders are subjective. The worker complains of general asthenia and anorexia. Associated movements become more difficult to carry out and require sustained effort. This leads him to economize in such movements. He grows apathetic and dull, losing any desire to talk to his workmates. This manifestation is particularly characteristic in otherwise very talkative subjects.

Quite often there is a period of mental excitement, which may lead the man's relatives to suppose him deranged, and this may be called the "manganese psychosis". The gait is at this time staggering, talk incoherent and logorrhoeic, and the patient becomes aggressive. At the same time a period of sexual stimulation may be manifested followed usually and quickly by impotence. This last feature is met with in nearly $80 \%$ of patients, and quite often among miners in contact with manganese. A period of apathy supplants these phases of excitement. The patient is not concerned about his condition, and this indifference becomes more marked as the disease progresses.

A marked somnolence is also observed, most often to be replaced later by stubborn insomnia. Lumbar pain and cramps in the lower limbs are frequent. These pains are made worse by effort. Some patients complain of headaches and giddiness.

Despite the difficulty in taking histories, due mainly to the patients' slowness of speech as well as their great emotionalism, the symptoms have been classified according to their incidence (Table 3).

These signs vary a great deal from patient to patient. They may be more or less clear cut, single or multiple, and appear in any order. But in general they mark the onset of the illness. In addition they reappear during the established phase, more or less accentuated. In view of the incurability
TABle 3

SUBJECTIVE SYMPTOMS

\begin{tabular}{|c|c|c|c|}
\hline $\begin{array}{l}\text { Sexual symptoms } \\
\text { Asthenia } \\
\text { Somnolence }\end{array}$ & $\begin{array}{l}\cdots \\
\cdots \\
\cdots \\
\cdots \\
\cdots\end{array}$ & $\begin{array}{l}\cdots \\
\cdots \\
\cdots \\
\cdots \\
\cdots\end{array}$ & $\begin{array}{ll}. . & 83 \% \\
. . & 77 \% \\
. . & 57 \% \\
\therefore & 56 \% \\
. & 51 \% \\
. & 38 \% \\
. & 16.5 \% \\
. . & 11 \%\end{array}$ \\
\hline
\end{tabular}

of manganese poisoning their importance in the early detection of toxicity is plain. As the evolution of the disease is usually slow, their recognition makes it possible to withdraw the workman from danger before the appearance of irreversible lesions. Unfortunately, the detection of these symptoms, mostly subjective, as well as the interpretation of the results of examination, is always very difficult.

The Intermediate Phase.-In the course of the preceding subjective manifestations, or very slightly succeeding them in time, certain objective symptoms may develop. The earliest are disturbances of speech. The voice becomes monotonous, lacking pitch and modulation. Words are slow, irregular, and badly articulated. Very often there is stuttering, especially when the patient is questioned. One also finds sudden halts during which no sound emerges. After having been, as it were, " blocked" for a few moments, words can then flow again correctly. Movements of the lips and tongue are very limited. From simple difficulty in articulating words, and then stuttering, complete muteness is reached during the established phase.

Nearly at the same time as these speech disorders changes in the facies may come. These constitute the "masque manganique", a facial expression at once jovial and fixed, which gives the patient a dazed appearance.

Expression of emotion tends to disappear though it is possible to make voluntary facial movements normally except in patients with a permanent grin, for whom it is more difficult. This early symptom is explained by an increase in tone of the facial muscles. According to the patient the face may remain impassive or be lit by a benign smile. This characteristic appearance is quite often interrupted by spasmodic laughs. When a number of patients are gathered together, this laughing spreads infectiously, mostly evoked by trivialities and quite disproportionate to the events or motions provoking it. Spasmodic weeping has been encountered only exceptionally, most of the patients being more often in a perpetual state of euphoria. Nevertheless, about a third weep spasmodically during questioning. 
There is also a certain clumsiness in movements, more especially those of the upper limbs. Movements are more or less markedly slowed and become uncertain. This is particularly striking in occupational movements. Thus with a miner at the face, one finds an increase in the number of working accidents, such as the loss of fingers, while others complain of their difficulty in drinking and in eating their food. Tremor is not the cause, but clumsiness. To this is generally added a marked hyperemotionalism. Without there being any question of imitation, and quite involuntarily, these patients exaggerate their ailments once they are observed. Hyperemotionalism continues to develop throughout the disease.

Certain movements become more difficult to perform : to climb or descend ladders, to lift weights, to sit down on the ground without falling over backwards, as well as getting up again. A gentle push from in front causes loss of balance and a fall. Walking may still be perfectly normal, except when swinging the arms. The first difficulties occur walking down hill, walking on narrow bases such as walls, and in the half-turn. Running soon becomes impossible. Walking backwards is more difficult and in some cases is accompanied by retropulsion and loss of balance.

One also finds adiodokinesis. Neurological examination shows nothing specific except a certain exaggeration of reflexes in the lower limbs. The disorders of the intermediate period have been classified in Table 4 in order of frequency.

TABLE 4

DISORDERS OF THE INTERMEDIATE PERIOD

\begin{tabular}{|c|c|c|c|c|c|c|c|c|}
\hline \multicolumn{5}{|c|}{$\begin{array}{l}\text { Clumsiness of movement } \\
\text { Exaggeration of reflexes in lower limbs }\end{array}$} & & $\cdots$ & $\cdots$ & \multirow{8}{*}{$\begin{array}{l}82 \% \\
74 \% \\
71 \% \\
70 \% \\
65 \% \\
47 \% \\
45 \% \\
32 \% \\
30 \%\end{array}$} \\
\hline Hyperemotionalis & & .. & .. & $\because$ & $\cdots$ & : & & \\
\hline Speech disorders & & .. & .. & .. & . & . & .. & \\
\hline Masque manganic & & $\cdots$ & $\cdots$ & .. & . & . & . & \\
\hline Spasmodic laught & & & . & $\cdots$ & $\cdots$ & . & $\cdots$ & \\
\hline Difficulty in certa & n m & ements & $\cdots$ & $\cdots$ & & $\cdots$ & $\cdots$ & \\
\hline $\begin{array}{l}\text { Spasmodic tears } \\
\text { Adiodokinesis }\end{array}$ & $\cdots$ & $\cdots$ & $\cdots$ & $\cdots$ & $\cdots$ & $\cdots$ & $\cdots$ & \\
\hline Adiodokinesis & $\cdots$ & $\cdots$ & $\cdots$ & .. & $\cdots$ & . & & \\
\hline
\end{tabular}

The Established Phase-Generally in a few months the evolution of the disease manifests itself by an aggravation of both subjective and objective symptoms as well as by the appearance of disorders of walking.

At this stage muscular hypertonia in extension is undoubtedly the essential symptom dominating the clinical picture. It is almost always marked in the lower limbs and face and is constant in the sense that it never completely relaxes, but it may be intensified either spontaneously or during movement. Hypertonia is expressed as muscular rigidity, which is seen as a characteristically slow, spasmodic, staggering and sometimes high stepping or swinging gait (Fig. 1). The patient starts with his trunk bent forward as though he were trying to drag his feet from the ground. The steps are short and hesitant. He moves with legs spread apart and knees stretched. Sometimes the feet seem to be flung forward, the toe describing a half-circle at each step. Eventually the patient is able to progress normally by putting his feet flat on the ground. In the majority of cases purchase is obtained with the ball of the foot, and this is the gait named "Hahnetritt" or "pas du coq" by Von Jaksch (1907) (Fig. 2). Only rarely is the contact made along the external border of the foot. Some patients are able to progress only when supported by another or with a stick (Fig. 3). The staggering so often seen does not appear to be of cerebellar origin but rather due to hypertonia which, slowing down the automatic movements conserving balance, obliges the patient to walk with straddled legs. Walking backwards is impossible, the patient who attempts it falling backwards at once or after a few steps. Climbing up or descending a ladder has long since had to be abandoned, and it is often impossible to maintain balance standing upright with feet together.

The half-turn becomes progressively more difficult, the patient achieving it by little steps, very slowly. In certain cases it becomes impossible, the sick man losing his balance and falling. Walking on uneven ground, and especially on hills, is a source of frequent falls. If it is found possible to climb a stair by the aid of banisters and successive tractions on the legs, going down is virtually impossible. The patient sits down and lets himself slide from step to step.

In those whose muscular power remains intact lifting even light weights from the ground is impossible since once the weight moves the subject loses his balance and falls forward.

In a general way even an extremely light push backwards makes the patient topple over in spite of the angles of support having been strengthened by straddling his legs. Crouching usually leads to falling backwards, the patient being able to rise again only with difficulty.

Most voluntary gestures are carried out very slowly. If they are more or less complex the subject breaks them up, leaving a gap between each. Abnormal tiredness rapidly develops and the patient interrupts his efforts by long periods of rest.

Along with these symptoms, and closely associated with the muscular rigidity, one begins to notice tremors. These may either be spontaneous 


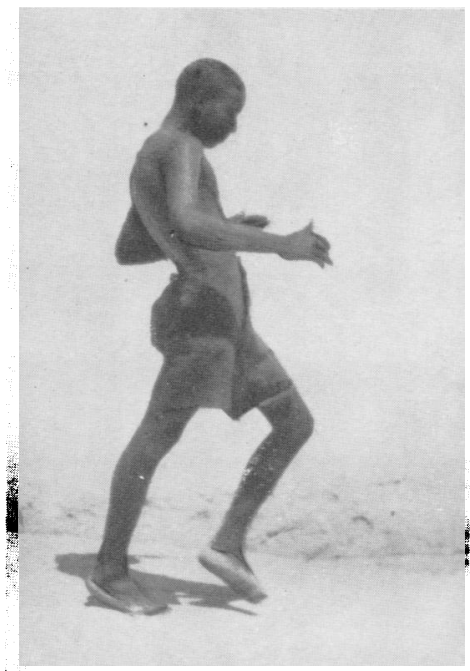

Fig. 1.

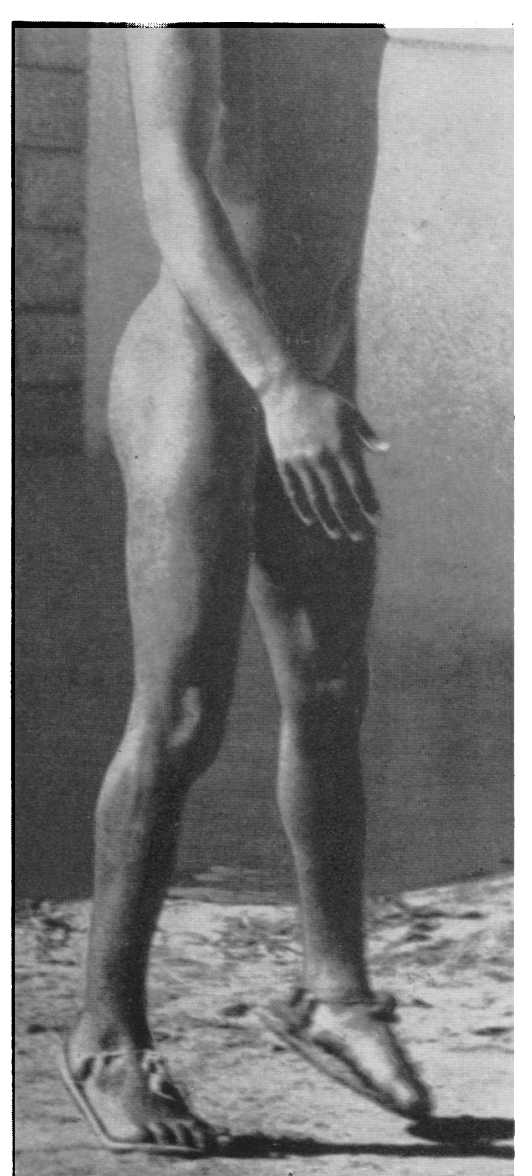
FIGS. 1 to 3 .
. illustrate the disorders and peculiar patterns of gait described.

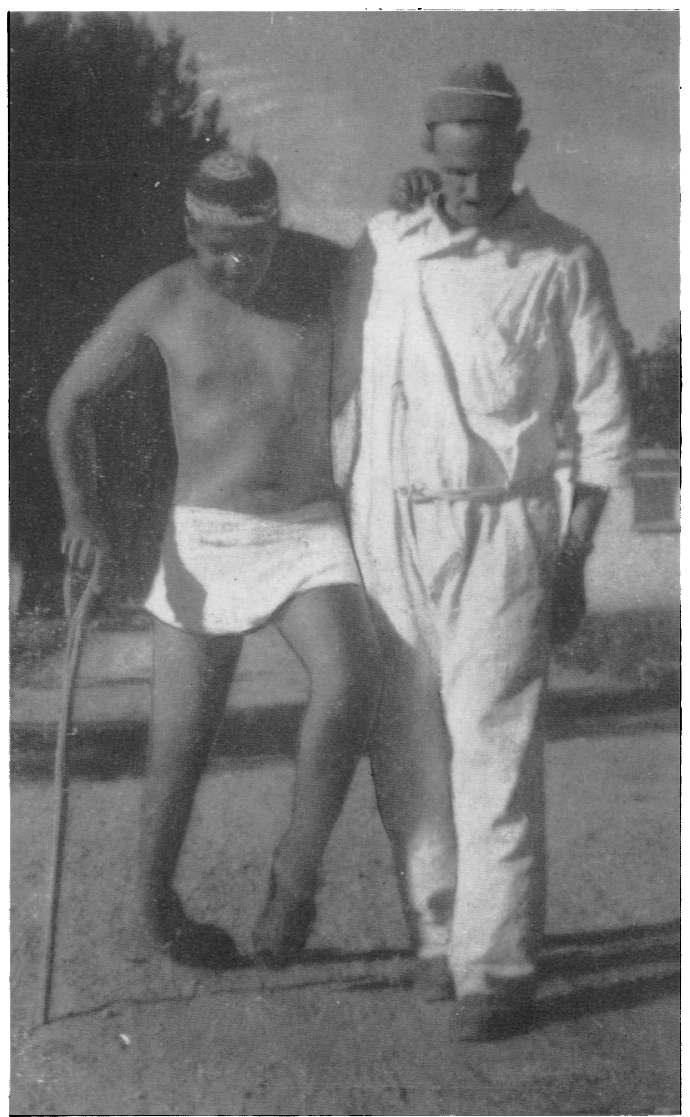

Fig. 3.

$(37 \%)$ or brought on by fatigue, emotion, or cold $(47 \%)$. Usually they affect the upper limbs, less often the legs, and are of moderate amplitude and frequency, rhythmic, and regular. Exceptionally generalized shaking may involve the whole body, and affect arms and legs equally.

The low standard of education of the patients has prevented us investigating systematically disturbances of writing. None the less in two of them its irregularity has been studied. Now and then certain words are wholly illegible. The shaky, though at first normally sized, letters become smaller and smaller. From time to time the writer stops to rest and on his resumption the letters are again a normal height (Fig. 4). The symptoms of the onset are at the same time considerably intensified. The fixed expression is still more pronounced and the facial animation that usually accompanies speech vanishes completely. In one case the hypertonia and contraction of the face were such that they led to permanent closure of the mouth ; in another nearly 


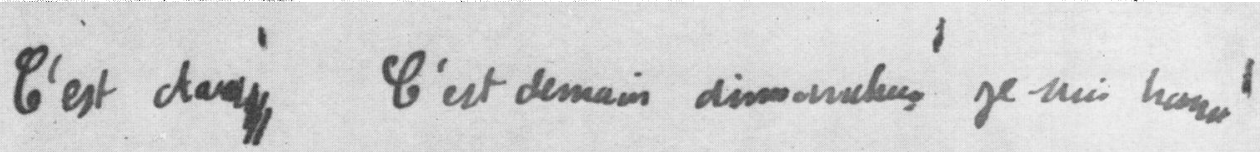

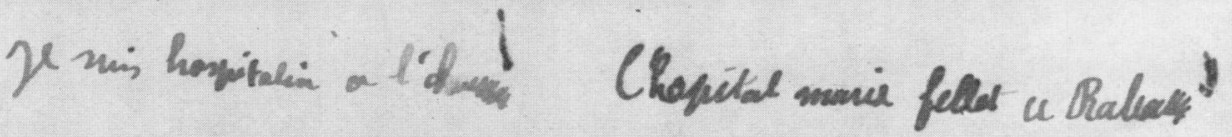

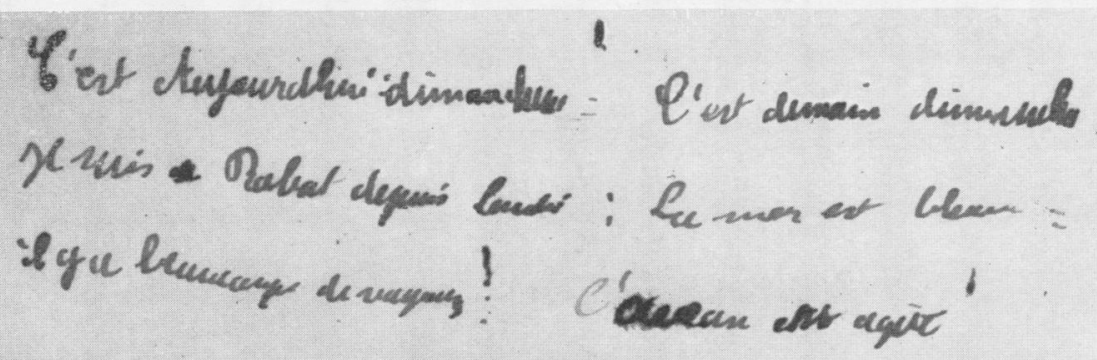

FIG. 4.-Characteristic examples of handwriting showing normal outlines here and there.

permanent occlusion of the eyelids was observed, so much so that they had to be held apart with the fingers so that the patient could see where he was going or to eat. His sight was perfectly preserved.

The spasmodic laughter is more and more frequent, while indifference is complete.

Tranquilly euphoric, the patients display the gravity of their condition without appearing to be affected by it and without putting forward any claims to attention. They complain only of a complete helplessness. Mental disturbances may perhaps be resolved (19\%). Loss of memory is exceptional. Sensory functions are intact. Digestive troubles have never been encountered.

The difficulty in questioning these patients is mainly due to their slowness of speech and to their very great emotionalism.

Disorders of locomotion are met with in all subjects.

A pyramidal syndrome rarely occurs. None the less it must be kept in mind since apart from exaggeration of the tendon reflexes one may elicit some Babinsky responses and foot and patellar clonus. Thirty-nine per cent. of patients present one or more of the three types of emotional disturbance. According to the subject the faculties are blunted, faulty, or absent. Vasomotor and secretory disorders may be encountered, in particular excessive sweating $(18 \%)$. On the other hand the excessive salivation mentioned by different authors is rare $(5 \%)$. In spite of the gravity of the neurological signs, the general state of Moroccan patients usually remains excellent. Their musculature is generally conserved. In contrast a certain number of deformities may appear and become permanent. I have seen a case of torticollis fixed by contraction of the left sternomastoid (Fig. 5). Most of the time they are confined to the feet and hands. Exceptionally, clawing of the hands (Fig. 6) and of the toes have been noted. Some other patients have fixed varus deformities with weight bearing on the outer border of the foot. These deformities make walking extremely difficult. Some patients are able to get along only on their knees, others become bedridden. The poisoning develops with varying rapidity and

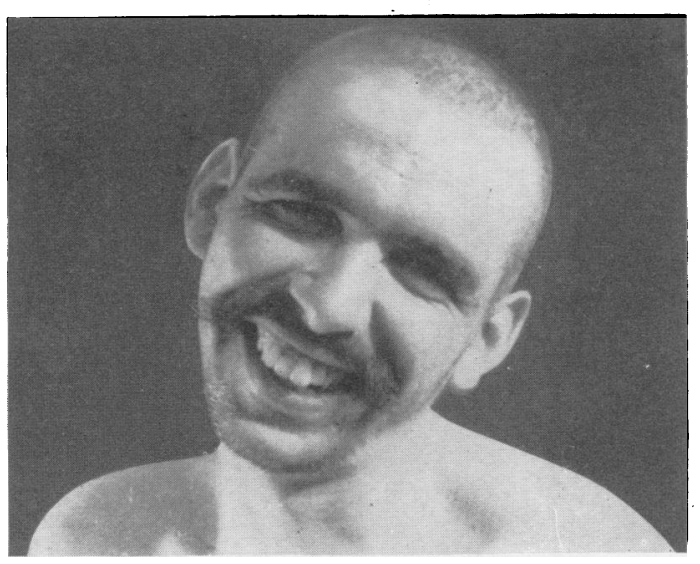

FIG. 5.-A case of torticollis. 
Fig. 6. - Deformities of the hands

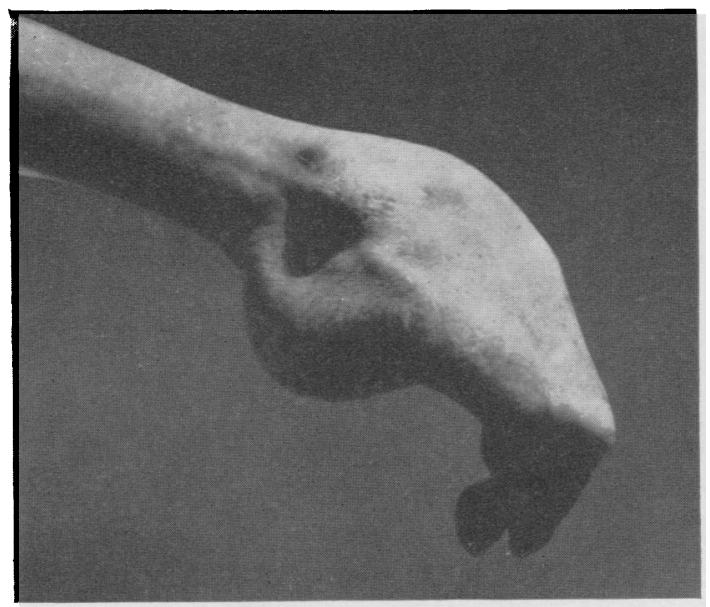

establishes itself in varying degrees. Thus graver and less grave forms will be met with, the bedridden type, however, being exceptional.

\section{Development of the Disease}

In considering the symptomatology of this condition its progressive character has been seen. Those cases which sometimes recover if they are withdrawn promptly from dangerous work will not be considered but discussion will be confined to those victims in whom the established lesions have caused disability. Table 5 shows the distribution of the degrees of invalidism.

TABLE 5

DEGREES OF INVALIDISM

\begin{tabular}{c|c|c|c|c|c}
\hline $\begin{array}{c}\text { Degree of } \\
\text { Disability }\end{array}$ & $\begin{array}{c}\text { Up to } \\
25 \%\end{array}$ & $25-50 \%$ & $50-75 \%$ & $75-100 \%$ & $\begin{array}{c}\text { Needing Support } \\
\text { from Another } \\
\text { Person }\end{array}$ \\
\hline Cases & - & 8.6 & $19 \cdot 6$ & 67.5 & $4 \cdot 3$ \\
\hline
\end{tabular}

The degree of disability is on the whole high. Moreover, the disabilities are not definitive, in the sense that they can become worse in the course of years. It is for this reason that legislation allows victims recourse to arbitration in the event of aggravation of their symptoms. In no case must the slowness and tenacity of the progress of the disease be forgotten. It is inexorable : once established it does not regress.

In all the patients examined the nervous disorders showed, after the patient had stopped work, no tendency to regress but I have been notified of two patients with disorders of walking which finally disappeared. These patients have not

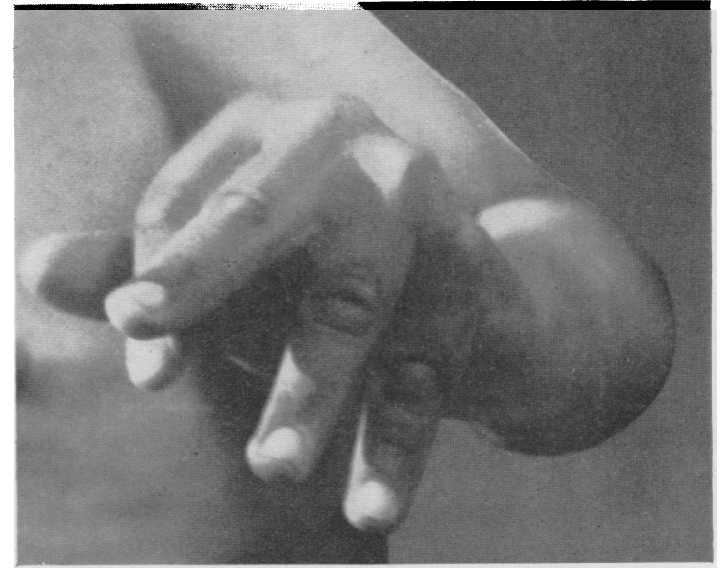

been found again, and the accuracy of these facts has not been verified. However, certain symptoms can diminish and even disappear, in particular the disorders of speech and the tremors. On the other hand those of walking are not altered. Two patients had ceased to have any contact with manganese, one for three years, the other for four, when their first symptoms appeared.

The explanation of the mechanism of this evolution has been investigated by various authors. I agree with those who think that once manganese gains entry to the body it is eliminated only very slowly. I have, in fact, found in one patient, who had given up his work 17 years before, $72 \cdot 2 \mathrm{mg}$. of manganese eliminated per kg. of hair. Another eliminated $254 \cdot 33 \mathrm{mg}$. 11 years after stopping work, while in a further example $174.7 \mathrm{mg}$. per $\mathrm{kg}$. of hair was eliminated two years after stopping work.

We have not been able to determine in which organs the metal is deposited since it has not been possible to perform a necropsy on a victim of this poisoning, but it seems that slowness of elimination allows the disease to develop though the patient is out of all contact with the toxin and thus favours the establishment of progressive and irreversible lesions.

\section{Manganic Pneumopathies}

Certain writers (Brezina, 1921 ; Bubarev, 1931 ; Baader, 1932 ; Büttner and Lenz, 1937 ; and Jötten, 1942) have described pneumonia caused by manganese, and, from the experimental point of view, the remarkable investigations of Lloyd Davies (1946) have defined the role played by manganese in pneumonia.

Lack of time and the necessity of seeing the disease as a whole have prevented us so far from making a detailed study of the problem. 
It is not proposed to consider the clinical picture of the pulmonary complications seen among manganese workers but some observations and figures gathered in the course of our studies will be given.

In Morocco Cauvin (1943) had already pointed out during the winter of 1939-40 the importance of the pneumonias and the high death rate associated with them. A comparable incidence did not occur again until 1947, a year which was undoubtedly the worst. Because of difficulties resulting from the war housing and sanitary conditions were deplorable. At once schemes were launched which greatly improved nutrition, housing, and personal hygiene, and since then these serious pulmonary disorders have not been a problem of such magnitude. However, the epidemic led us to suppose that manganese could not be the sole aetiological factor at work. It could, on the other hand, undoubtedly be an aggravating element. Approximately (excluding bronchitis) $3.7 \%$ of workers are affected each year with pneumonia and other respiratory diseases with an average morbidity of $11 \%$. Bronchitis, confused as it is with common ailments, does occur frequently among manganese miners.

The clinical signs of manganese pneumonia are at first those of acute alveolar inflammation. The extremely violent character of this condition, which becomes very serious almost at once, may mislead the doctor. Dyspnoea is marked, respiration shallow and gasping. Cough and expectoration are rare. The illness alters, however, after the third day from a frank pneumonia to less well defined localization and discrete pleural involvement. About this time too is seen the characteristic facial cyanosis. A fatal issue may ensue from heart failure between the fifth and the tenth days. It may also occur suddenly in patients regarded as cured. The usual drugs, in particular sulphonamides and antibiotics, mostly are without effect.

We have found specially notable among the few patients whom we have seen with this condition, a leucopenia with relative polynucleosis, an enormous rise in the erythrocyte sedimentation rate (120 in the first hour using a Westergren tube), and eosinophilia in the sputum.

Many investigations are still needed to study this special aspect of manganese poisoning. Unfortunately, the isolation of the mining districts has up to now prevented our getting the usual $x$-ray films and local customs forbid our doing necropsies. Thus it is difficult to be sure whether one is dealing here with an ordinary pulmonary infection complicated and aggravated by manganese, or subacute oedema, the pulmonary manifestation of a toxic state.

\section{Individual Susceptibility}

If the number of cases of manganism are related to the number of workers in the mining industry it is seen that the incidence is very low in comparison with the total. This is still more striking when the fluctuating nature of the local pool, which involves a constant inflow of workers, is considered. On the other hand, if it is conceded that only the pulverized ore is liable to produce poisoning the percentage of persons affected is high. (We have tried to establish the statistics but unhappily the lack of registration and the perpetual changes again prevent us from presenting useful figures.)

Apart from subjects showing neurological organic lesions or having previous meningitic or encephalitic conditions, it is difficult to foresee that an individual will tolerate exposure to manganese badly. On the other hand lesions of the excretory system (liver, kidneys) seem important in view of the very slow elimination of manganese by the body. But what appears most interesting, from the point of view of individual susceptibility, is the state of the respiratory tract and more particularly the ability of the pulmonary alveoli to cleanse themselves of manganese dust. If each day the subject manages to get rid of most of the inhaled particles, intoxication will not ensue. It is necessary in some way to balance the intake and output of dust. So long as manganese particles are not got rid of in a satisfactory fashion they are absorbed and will produce irreparable neurological lesions. Unfortunately, this threshold cannot be determined at present either clinically or in the laboratory. In the interests of prophylaxis, therefore, only those with sound pulmonary and nervous systems should be employed as manganese workers.

It has often been suggested that alcoholism and syphilis are of importance in determining individual susceptibility to manganese poisoning. We do not consider these factors of appreciable importance. So far as the former is concerned only one of our patients drank alcohol ; as for the second only $10 \%$ gave positive serological reactions. The others had never had any specific treatment.

We tentatively suggest the possible influence of carbon monoxide. Ventilation is often deficient, with the result that carbon monoxide is found in the atmosphere in certain workings. For example we have obtained readings varying from 0.01 per 1,000 to 0.05 per 1,000 . While this gas is not in sufficient quantity to produce serious accidents, it may perhaps favour the establishment of neurological lesions by manganese poisoning. 
There does not seem to be any bias between the sexes on the incidence of the disease. It is true that underground work, which alone produces poisoning, is forbidden to women. So far as age is concerned (Table 6) it would appear that the critical age for intoxication lies between 30 and 40 years.

TABLE 6

AGE RELATED TO INTOXICATION

\begin{tabular}{c|c|c|c|c|c}
\hline Ages & $\begin{array}{c}\text { Up to 20 } \\
\text { Years }\end{array}$ & $\begin{array}{c}20-25 \\
\text { Years }\end{array}$ & $\begin{array}{c}25-30 \\
\text { Years }\end{array}$ & $\begin{array}{c}30-40 \\
\text { Years }\end{array}$ & $\begin{array}{c}40-50 \\
\text { Years }\end{array}$ \\
\hline$\%$ sick & 0 & 17.1 & 27.6 & 43.5 & 11.8 \\
\hline
\end{tabular}

This factor cannot be regarded as absolute, since it would be necessary to know the age distribution of the whole labour force, and this is very difficult.

\section{Biological Changes}

We have carried out many investigations of sick patients, suspects, and those considered healthy in an attempt to find a test for manganese poisoning. We propose to publish elsewhere the results of this study, which involves more than 10,000 analyses.

While we have not found an absolutely indisputable test, it none the less appears to us that the victims of manganese poisoning display certain changes in the white cell count, the rate of excretion of the 17-ketosteroids, and the basal metabolism.

White Cell Count.-In $52 \%$ of patients we found a change in the white cell count with a relative increase of lymphocytes and a decrease in the number of polymorphonuclear cells.

Excretion of 17-Ketosteroids.-There is without question a disturbance, $81 \%$ of our patients showing a diminished excretion.

Basal Metabolism.-Employing our usual techniques for measuring basal metabolism we found that it was increased in $57 \%$ of cases, often to a very marked degree. Had it been possible for us to use Durupt's effort test in all circumstances this percentage would have been still higher. Most of the patients whom it has been possible to test have given a positive result.

\section{Elimination of Manganese}

It is incontestable that, as for other metals, the toxicity of manganese is controlled on the one hand by the ease with which it enters the general circulation and on the other by the gap between absorption and excretion.

All the manganese that penetrates to the general circulation is not integrally fixed. A large part is excreted. The liver, thanks to its detaining power, plays an important role since it excretes manganese in the bile, and so the faeces form the chief route by which it is eliminated. Thus the average quantity of manganese we have estimated in the faeces is $54 \mathrm{mg}$. per $\mathrm{kg}$. Another route, though less important, is in the hair, and we have recovered in various groups of subjects the following amounts in milligrams of manganese per kilogram of hair :

$$
\begin{aligned}
& \begin{array}{llll}
\text { Apparently healthy subjects } & \ldots & 365 \\
\text { Suspected subjects } & \text {. } & \ldots & \mathbf{2 3}
\end{array}
\end{aligned}
$$

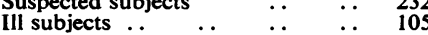

Elimination is less in suspects and in the sick than in apparently healthy men. Of course, the sufferers from manganism had mostly been away from work for several years but the suspects were in contact with the ore to the same degree as the apparently healthy. It must therefore be supposed that those affected are more especially those in whom the elimination of manganese is deficient or extremely slow, as we have already seen in connexion with the development of the illness. Urinary excretion plays but a minor part and is found in only about $10 \%$ of subjects. Manganese in the urine varies then from 16 to $500 \mathrm{mg}$. per litre.

\section{Pathogenesis}

Manganese gains access to the body by the pulmonary and digestive routes. In our view the latter is not of interest. In fact, apart from jobs where crushing raises a great deal of dust, we have not found manganism even in the washing plant, and yet these workers absorb really large quantities of manganese by mouth and from the hands. Furthermore, we have verified experimentally the lack of toxicity of the metal so ingested. It seems that this may be partly due to the poor absorption of mineral by the body during its passage through the intestine, and perhaps also because particles not absorbed directly after their formation lose most of their toxicity. The pulmonary tract is undoubtedly the major route for penetration and also the only dangerous one. Dusts of less than 5 microns reach the alveoli and are then in contact with phagocytes which, after ingesting them, bring them into the general circulation by means of the lymphatic channels. We have recovered from the sputum some of these cells enclosing manganese particles. Apart from this mode of penetration there is probably some absorption of dust by solution through the alveolar mucosa.

Some writers, struck by the really negroid appearance of manganese miners, have for this reason tended to attach great significance to cutaneous penetration. Experimental trials with dusting and controls by analyses of manganese in the 
tissues have demonstrated that this hypothesis carries no weight.

On no account must the fact be forgotten that the area of the alveolar epithelium represents about 25 times the surface of the skin, and otherwise offers an ideal situation for penetration of the organism by the dusts which come in contact with it during respiration.

\section{Conditions of Toxicity}

Among the factors which condition the toxicity of the manganese ore dusts, the chief is certainly the number of particles less than 5 microns in size. To this must be added the content of the dusts in toxic metal and hence the richness of the mineral. This last factor varies a great deal with the type of ore. It also differs according to the mine and even sometimes in individual workings according to the seam.

Let us compare the number of cases of manganese poisoning per mine (Tiouine 106, Imini 32, BouArfa 12) with Table 7 which indicates the average dustiness in the workings at Tiouine and Imini and at different work points. We note that a con- siderable difference exists from the point of view of risk of poisoning between the rocky type of ore (Tiouine) and the friable or powdery type (Imini). In the first case the amount of dust is considerably greater and most of it falls into the category of noxious particles less than 5 microns in size. However, the amount of fine dust and the manganese content do not explain all the toxicity of dusty areas. Thus at the sinterization works at Sidi Marouf the amount of dust and the manganese content are very high but a case of manganism is rarely encountered there. So far as the miners themselves are concerned, by far the greatest number of cases occur among rock-drill operators. However, the degree of dustiness is still considerable in the galleries and workings where only hand-picks are used, as indeed also in surface installations. The only difference is that the method of extraction, which involves the use of the rock-drill for stony ores, gives rise to fresh dusts, whereas the method of working the powdery ore (which is in any case slightly damp) and its sinterization rather stirs up dusts back into suspension, the pulverization itself being only accessory. It appears that old dusts

TABLE 7

AVERAGE DUST COUNTS

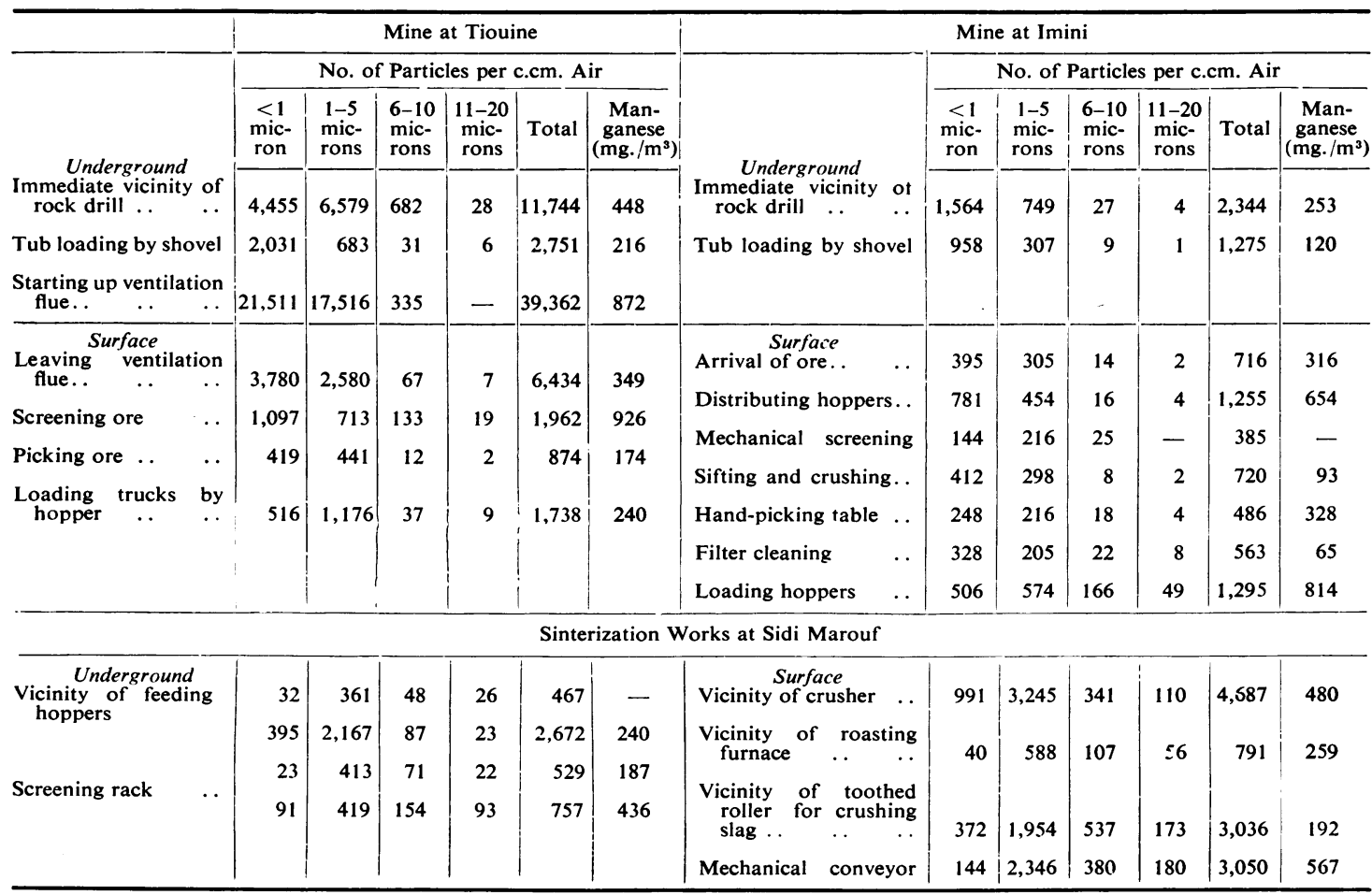


stirred up again in suspension do not seem able to produce intoxication and ought to be qualified as " dead". One is, then, led to speculate whether, as soon as it is crushed, the dust does not undergo physico-chemical modifications such as superficial oxidation, alteration of surface, or electric change which might diminish its toxicity.

Judging by analyses of the ores, it does not seem that their toxicity is in strict relation to their composition. However, it is worth noting that the ore at Tiouine which causes most of the cases of poisoning is less oxidized than that at Imini and at Bou-Arfa.

From the mineralogical point of view it appears that the most dangerous manganese ore is braunite, and in particular the crushing operation which conditions the toxicity.

The possible activating role played by certain metals or alkaline-earths associated with manganese in the ores must not be forgotten. Lead, which is present in considerable quantity in some deposits, seemed especially interesting. However, despite our researches we have failed to detect any symptoms of lead poisoning among the miners.

In the face of all these elements it is very difficult to lay down exactly what quantity of dust and of mineral is necessary to produce intoxication. It is, however, rather odd to note that while the illness appeared on an average after 18 months of work at Tiouine and four years at Imini, it takes about $13 \frac{1}{2}$ years to manifest itself at Bou-Arfa. From a biological point of view the highest grades of manganese are met with at Tiouine and this confirms the importance of the degree of breakdown into fire particles.

Furthermore, it is evident that the longer the exposure to a foul atmosphere the greater the risk of intoxication. To the length of stay in dusty surroundings is also to be added the increase in volume and the number of respiratory movements caused by fatigue and physical effort. The quantity of dust inhaled is thus directly related to the occupation of the worker and the conditions of his environment (temperature, humidity, foul atmosphere).

Too many factors are interwoven for it to be possible to lay down in an exact and absolute manner a limit for atmospheric manganese. Our checks of dusty atmosphere lead us to think that a prophylactic system which would keep the number of particles less than 5 microns down to 1,500 per cubic centimetre of air and the manganese content to 100 milligrams per cubic metre of air would on the whole be satisfactory. Even so, it would not completely eliminate all danger of poisoning; nor can all the other factors we have successively studied be neglected. To be of value any prophylaxis must be adapted to each type of mining operation and to the ore.

\section{Treatment}

So far as we know there is no treatment for manganese poisoning when it reaches its established phase, but the usual palliative drugs for rigidity and tremor can be used. We have never, in spite of all our investigations, observed any definite improvement, still less regression of the symptoms. It has been the same with the treatment advised by Charles (1927), based on liver and trials of group B vitamins in small and large doses. Physiotherapy and electrical treatment, admittedly carried out with inadequate means, have been inconclusive.

The only possible treatment is immediately to withdraw from work anyone presenting the first symptoms of intoxication. From that moment the aim must be to rid the system completely of the manganese.

We have tried numerous products experimentally over several years and for a long time these trials proved unfruitful. The discovery of the antitoxic action of calcium versenate on manganese allows us to envisage the use of this substance in occupational poisoning by manganese and its derivatives (Rodier, Mallet, and Rodi, 1954). Indeed calcium versenate provides an interesting means of fixing manganese in a non-toxic and readily excreted form, but its use as a prophylactic can only be regarded as an agent for the elimination of manganese, given at regular intervals in such a fashion as to avoid an accumulation of the metal.

From a therapeutic point of view it is difficult to see how it could be used in patients with established neural lesions since these are irreversible. However, for patients in the early stages of poisoning its action on excretion might perhaps prevent the inexorable evolution of the disease towards total and permanent incapacity.

\section{Prophylaxis}

What we have observed concerning the conditions of toxicity of dusts and their penetration by the pulmonary route simplifies and at the same time complicates the problems of prophylaxis. Technical measures will have to be applied above all to those working positions where the ore is crushed. So far as medical measures are concerned there is no need for them to be applied in the same way for all workers. The frequency of periodic examinations will depend on the type of work done. It would be pointless to put a miner operating a rock-drill and 
one directing mine-tubs on the same system of medical surveillance.

The organization of the medical service should be directed towards protecting the worker by supervising his state of health from his engagement throughout the course of his employment in the mine.

Examination on First Employment.-This examination aims principally at determining the aptitude of the individual and alloting him to the job which will suit him best. In the case of manganese mines it is wise to exclude from dangerous operations, and in particular those which involve the pulverization of ore, a certain group of subjects whose physical condition leads one to presume that they will tolerate manganese badly.

Those who should be regarded as unsuitable are men with lesions of the excretory organs, the liver and kidneys, blood disorders, organic lesions of the nervous system, progressive pulmonary diseases, and those with a past history of meningeal or encephalitic disturbance. A medical dossier will thus be established for each employee considered suitable for work with manganese.

Periodic Medical Inspections.-The gravity of manganese poisoning demands in effect a detection of pre-manganism so that irreversible neurological manifestations may be avoided. The time that elapses between first contact with the metal and the appearance of neural lesions is of varying length. During this latent period it is reasonable to suppose that functional disturbances may precede organic lesions. The demonstration of such disorders would constitute an excellent clue to pre-manganism. Unfortunately in spite of our researches we have not been able to discover an absolutely specific test for pre-manganism. However, periodic examinations will allow the subjective and objective signs of intoxication to be observed. This examination will be completed as far as possible by certain biological analyses whose importance we have come to recognize in the course of our studies and investigations.

The frequency of these examinations will depend upon the danger of the work. Examinations of rock-drill operators should take place every two months; for other underground workers, ore loaders, conveyors, they should be six-monthly. For the rest of the personnel, and in particular for surface staff, an annual examination should suffice, but from this latter category must be excluded workers who may find themselves in an area where ore is pulverized. For these the same measures should be taken as for rock-drillers.
As well as the usual clinical examinations and the search for early symptoms of intoxication, we advise that particular attention should be paid in the course of routine visits to the following symptoms and tests be carried out :-

In the course of questioning note speech defects and look for diminution or absence of expression and at the same time notice signs of emotional disturbances. Watch for hypertonia, tremor of the extremities, disorders of equilibrium. On a second occasion submit the man to a series of tests including walking slowly and fast, both forwards and backwards. This test will be completed by walking up hill or, even better, climbing a vertical ladder. A half turn from the halt, and walking; pushing test ; trial squatting; search for adiodokinesis (with the marionette test); lifting weights; and in addition, if the general education of the subject permits, a writing test.

A comparative study of the results of these various tests and those of the clinical examination should allow the doctor to make an accurate assessment of the development of poisoning.

Examinations on Resumption of Work.-It is essential if these routine examinations are to be completely efficacious to examine afresh every employee who has stopped work for any reason. Only such an examination can determine if the work may be continued under the usual conditions.

As a consequence of these examinations men presenting the following symptoms of poisoning will have to be considered unfit : fixed facies, speech disorders, accentuation of slowness and clumsiness of movement, exaggeration of tendon reflexes, muscular spasticity, disorders of walking, any objective signs of involvement either of the pyramidal or extra-pyramidal nervous system.

It will be necessary to place under close observation subjects presenting subjective signs of poisoning such as asthenia, somnolence, anorexia, psychical excitement, muscular pains, impotence. The clinical examination must be completed by a white cell count. For such patients it is advisable to determine the basal metabolic rate, to carry out an estimation of the urinary 17-ketosteroids, and of the manganese level in the blood.

In persons presenting with lymphocytosis, a raised basal metabolic rate, diminution in the titre of the urinary 17-ketosteroids, a blood level of manganese of $250 \mathrm{~g}$. \%o will be regarded as suspect.

If clinical signs and biological changes are found in the same patient the examinations will be repeated at an early date (within 30 days). If the signs become accentuated the man will be considered unfit 
Unfitness for work liable to expose the individual to manganese poisoning is not necessarily unfitness for all other work. It is the duty of the employer and the medical service to examine all possibilities of re-employment in the company or out of it each time a change of employment becomes essential.

Technical Measures.-To carry out good prophylaxis against manganism it is very important to recognize that the operation which is dangerous above all others is crushing ore. This is the origin of almost all cases of poisoning.

So far as actual mining of the ore is concerned, the boring of charge holes and blasting are the operations causing most of the dangerous dusts. These two procedures give rise to clouds of dust of very different density and difficult to measure. In general, once the cloud is produced each particle is propelled at its own speed according to its diameter, its weight, and the draughts in the galleries. The danger from these particles will thus depend on the distance of the worker from the source of production. The risks run by underground workers other than those at the drilling or blasting points will therefore be variable and in practice very difficult to determine.

In the mines studied, boring blast holes is done dry with a pneumatic drill, and very rarely with hand-spike and sledge hammer. In the course of boring the quantity of dust emitted depends on the state of the rock, the fine dusts being increased by the hardness of the ore and diminished by moisture (our studies of dustiness in Table 7 demonstrate the importance of this particular factor in the rocky type of ore fairly rich in silica); the slant of the bore-hole; the rapidity with which it is bored; the escape of air from the drill which produces and maintains a truly artificial dust cloud.

Blasting we have classed among the greatest producers of dust and is particularly dangerous since it is the origin of numerous very fine particles. These are of high toxicity, for they sediment badly and remain in suspension for a long time in the air. We insist on the absolute necessity of shot firing at the end of the shift, and only once at a time. At the same time a substantial gap should be left between the departure of the first shift workers and the arrival of those of the next shift. If ventilation is not sufficient to evacuate the dusts and gas products of the explosion, as often happens in blind-end face workings, it must be supplemented by forced ventilation.

So far as ore cutting with hand drills, as principally used in mines with friable ore, is concerned, this method of exploitation undoubtedly presents less danger. However, according to the amount of dust produced, all danger cannot be completely eliminated, and here also ventilation will speed up the evacuation of dust.

Individual Protection.--It is customary when dusts and their dangers come up for discussion in a mining company to propose at once the use of a mask. Certainly it is sometimes impossible to clear an atmosphere of dust completely and it is only in this instance that one needs to consider using masks. In spite of the refinements which have been incorporated in some models, either in the improvement of air filtration or in lessening the discomfort caused to workmen, their use does not provide a sufficient guarantee of protection to manganese miners. It is only necessary to have followed the work in a mine gallery to know that a mask cannot be kept on during prolonged hewing and shovelling. Although the resistance of the respirator may be as slight as possible, each breath constitutes an effort for the worker, especially in the underground atmosphere where the temperature is considerable and the degree of humidity high. Respiration taking place by lowering pressure, the masks are not absolutely impervious to dusts. Finally manganese ore sticks together and adheres readily. Under the influence of exhaled water vapour, the filter plate soon gets clogged with the collection of dust ; respiration then becomes very difficult and the miner takes off his mask in a foul atmosphere.

We do not intend to reject out of hand the use of the mask as a means of prophylaxis. We would, however, wish that its use would not be considered until all other prophylactic measures have been found to be impossible. The choice of mask must not then be left to the administrative staff. It is necessary to choose something light, solid, and easily held in place and maintained. It should have a pre-filter that is easy to clean, and be furnished with an efficient disposable filter, interchangeable and non-hygroscopic. Masks using a sponge or any kind of pack impregnated with water are illusory. It is essential that the employer should make special provision for the upkeep of these masks. They must be inspected as often as possible in rotation and not simply distributed once and for all in the first place together with lamp, helmet, and boots.

Collective Protection.-In view of the difficulties of individual protection by masks, one sees the necessity of trying to eliminate dust at its origin, and more particularly at the drilling which is the most important source of dustiness. During dry boring 
with a pneumatic rock-drill, and apart from the pulverization of the ore, the miner is accustomed to clear the bore-holes with a jet of compressed air. This violent gush of air puts numerous particles into suspension in the atmosphere producing massive dust clouds in ill-ventilated places. Against this, the only efficacious measure is the employment of pneumatic rock-drills with water injection. It is only recently that we have been able to get these progressively introduced in certain workings. The difficulty involved in bringing up a water supply may be simplified by the use of water tanks mounted on mine-tubs. As the manganese beds are found in desert and pre-Saharan regions, it follows that difficulties in supplying water are sometimes insurmountable. The pumping-out of the mine seepage may in such instances provide an extremely valuable source of water.

Good damping of the dust can only be obtained after a sufficiently long contact of water with the ore, and demands a sufficient flow. Different types of pneumatic rock-drills with water injection are on the market and vary in the efficiency with which they eliminate. It again follows that company management should not choose their equipment except after carrying out varying tests or after having gained sound advice. However, water injection is not without some drawbacks. The worker using the apparatus is liable to get wet, especially at the beginning of boring since then the water has a tendency to splash back. In this event the miner has the unfortunate habit of beginning the bore-hole dry. Most of the time we have noticed that the inefficiency attributed to water injection is due either to this mistaken manoeuvre or to the workman, neglectful of the danger of poisoning, reducing or suppressing the flow. Another drawback of water injection is that it raises the humidity of the air and so makes work more difficult in a hot atmosphere. Despite all these drawbacks, this technique remains a very good means of combating dust and seems to be the most efficacious way of limiting manganese poisoning in the mines. In the event of there being no water, it will be necessary to resort to dust traps. Unfortunately, quite often in these devices the interception is inadequate and filtration even less efficient, for they allow a portion of very dangerous dust to pass.

All these measures directly applicable to the source of the particles need to be completed by general arrangements concerning evacuation of dust and general ventilation. Dust arising from shovelling, loading, and blasting can only be removed by a collecting system involving a gathering point, a channel without any inert zones, and eventually a point of discharge of the dust to the air. In spite of everything a good evacuation of dust still leaves a lot of particles in suspension, does not get rid of toxic gases, and does not replace the air. It is, therefore, necessary to complete the cleansing of the working by ventilation. This will have to be adapted to the mine in such a fashion as to avoid eddies which would be the cause of new dust clouds. The use of flexible ventilating pipes, less heavy and easier to manipulate than rigid tubes, appears to be recommended.

General Measures.-We have seen that manganese mostly penetrates by the pulmonary route. In underground work the physical effort needed is very great. It is rendered more difficult by the temperature, the humidity, and the foul air. The number of respiratory movements increase and tend to accentuate the risks of poisoning by raising the quantity of dust entering the body. It is therefore necessary to mechanize as much as possible the handling of ore generating toxic dusts.

The use of " pushers" for blocking-up the rockdrills and so avoiding great physical effort on the part of the miners seems to be a measure to be developed.

Concerning surface installations, it is absolutely indispensable to isolate from other operations the crushing of the ore and pneumatic washing which are both great producers of dust. To the greatest degree possible these processes should be carried out in closed and air-tight installations.

In order to ensure the full efficiency of these measures every company will be concerned to see that a technician is specially charged to check up on various anti-dust appliances. He will also have to ensure strict control of dustiness in the workings.

Finally a progressive organization will promote a rotation of personnel in such a way as to bring about a process of disintoxication by changes of duty. This is very important for rock-drill operators.

But all these measures will be merely speculative if each worker is not told of the dangers of poisoning and if management is not vigilant to see that the preventive means put at the workman's disposal are effectively used.

\section{Compensation Legislation}

Following the example of a number of countries, such as Great Britain, Germany, Chili, Switzerland, and the U.S.S.R., Morocco has listed manganese poisoning among the compensatable occupational diseases.

This legislation recognizes among the manifestations of manganese poisoning the nervous 
syndrome and pneumonia. It defines the work liable to produce it as the extraction, handling, and industrial use of the ores. This legislation is still not complete and will require recasting upon certain points. As a result of our researches we are studying at present a full text which will define the conditions of compensatory action, the medical measures to be applied in mines, and the prophylaxis to be instituted there.

It seems important to point out that the period of one year laid down under certain laws after which responsibility lapses is quite insufficient. We have seen a certain number of cases appear several years after stopping work, and it therefore seems reasonable that the period of responsibility should extend for five years. Legislation should also allow a plaintiff to obtain a revision of his pension in the event of his symptoms worsening. It is in fact known that a small percentage disability evolves more or less rapidly to a $100 \%$ incapacity.

\section{Summary}

This paper surveys recent knowledge of manganese poisoning among Moroccan miners. After a brief introduction on the manganese deposits where the disease is encountered, the clinical syndrome is described. One hundred and fifty cases of poisoning have provided the material for these investigations. Manganism is studied under its two aspects : the neurological syndrome progressing inexorably and irreversibly, and the pneumopathies. Individual susceptibility, whose role seems important in this condition, and the conditions for toxicity are successively discussed. The latter constitute one of the most difficult problems since prophylaxis depends directly upon it. Some problems, such as the part played by dust, are described. If at present treatment of the disease is only palliative and cannot produce regression of symptoms, the elimination of manganese by the use of calcium versenate opens new possibilities. An important section is devoted to problems of prophylaxis, and exact indications are given of both medical and technical measures to be taken. Finally certain legal aspects of compensation are presented and discussed.

The illustrations in this article belong to the author's collection or are extracted from the film "Manganism" produced by $\mathbf{J}$. Rodier in collaboration with J. Boyer and $R$. Chenay, the script writer.

\section{REFERENCES}

Baader, E. W. (1932). Arch. Gewerbepath. Gewerbehyg., 4, 101. Bergman, T. O. (1774). Cited by Geloso (1933).

Brezina, E. (1921). Internationale Übersicht über GewerbeKrankheiten. Springer, Berlin.

Bubarev, A. (1931). Gigiena Truda, no. 6, p. 85. Cited by Baader

(1932).
Büttner, H. E., and Lenz, E. (1937). Arch. Gewerbepath. Gewierbe-

hyg., 7, 672

Cauvin, F.'(1943). Maroc méd., 22, 16

Charles, J. R. (1927). Brain, 50, 30

Couper, J. (1837). Brit. Ann. Med. Pharm., 1, 41.

Davies, T. A. Lloyd (1946). British Journal of Industrial Medicine, 3,111 .

Geloso, M. (1933). In Traité de chimie minérale, ed. Pascal, P. vol. 9, p. 399. Masson, Paris.

Guyton de Morveau, L. B. (1785). Cited by Geloso (1933).

Jaksch, R. von (1907). Münch. med. Wschr., 54, 969.

Jötten, K. W. (1942). Arch. Hyg. (Berl.), 128, 301.

Rodier, J. (1950). Maroc méd., 29, 817.

C, Mallet, R., and Rodi, L. (1954). Arch. Mal. prof., 15, 210.

- and Rodier, M. (1949). Bull. Inst. Hyg. Maroc, n.s. 9. 3.

Scheele, C. (1774). Cited by Geloso (1933). 